\title{
Ueber die bei einer Systole gelieferte Bîtmenge.
}

$$
\text { Von }
$$

\section{J. L. Hoorweg.}

In Heft 11 und 12 dieses Archivs (16. Januar) S. 6015 findet sich eine Bemerkung des Herrn Herm an $\mathrm{n}$, welche den Zweck hat, aus den von L u dwig und Dogiel gegebenen Zahlen für die Gesehwindigkeit der Blutbewegung die Unwahrscheinlichkeit der neueren Ansichten über die Grösse des Secundenvolums darzuthun. L u dwig und Dogiel fanden wit der Stromuhr für die lineare Gesehwindigkeit des Blutes in der Carotis des Hundes 200 $-700 \mathrm{~mm}$. Wenn aber das Herz des Menschen in einem Schlage nur 50 bis $60 \mathrm{~cm}^{3}$ Blut entleert, so giebt das für die $23 \mathrm{~mm}$. weite Aorta nur eine Geschwindigkeit von 145 bis $200 \mathrm{~mm}$, also eine Geschwindigkeit, viel kleiner als die, welche $\mathrm{Lud} w \mathrm{ig}$ und Dogiel in der Carotis des viel kleineren Hundes fanden. „Da ferner", schreibt Hermann, "die Carotis einem grösseren Gesanmtquerschnitt angehört als der Aortastamm, also letzterer eine beträchtlich grössere Läıgegeschwindigkeit haben muss als die Carotis, so scheint mir hier ein sehr grosser und bisher ungelöster Widerspruch zu bestehen, auf welchen ich hinweisen wollte, da die niedrigen Werthe des Secundenvolums immer weiter in den Lehrcanon iuberzugehen scheinen."

Hermann theilt also die Meinung V olkmann's ${ }^{1}$ ) und von vielen Anderen, dass die Geschwindigkeit in der Aorta nothwendig. grösser sein soll als die in der Carotis, weil bei jeder Verzweigung der Gesammtquerschnitt zunimmt. Es ist aber klar, dass diese ältere Anschauung nur dann richtig wäre, wenn die Arterien sich nicht verzweigten. Alsdann wäre unzweifelhaft im grösseren Querschnitt die Geschwindigkeit geringer. Bei Verzweigung aber geht durch jeden Zweig gerade so viel als von dem Widerstande dieses Zweiges im Vergleich zu den Widerständen aller anderen Zweige bedingt wird. Die Blutmenge, $q$, die in einer Secunde in

1) Hämodynamik S. $20 j$ und 208. 
die Carotis einströmt, kann deshalb nur durch Versuche bestimmt werden. $q$ ist ein gewisser Theil des ganzen Secundenvolums $Q$, welches vom Herzen ausgestossen wird. Wie gross aber $\frac{q}{Q}$ ist, weiss man nicht, ist auch mit dem Tonus der Capillaren veränderlich ${ }^{1}$ ).

Viel kleiner als $1 / 5$ wird $\frac{q}{Q}$ nicht sein. Setzen wir aber $\frac{q}{Q}$ $=1 / 8$, so ist, weil die Durehmesser der Aorta und der Carotis sich wie 3:1 verhalten, die Geschwindigkeit in der Aorta doch nur $8 / 9$ von der in der Carotis.

Was man die lineare Geschwindigkeit des Blutes nennt, ist, wie ich schon früher bemerkt habe, eine Grösse, bei der Blutbewegung ohne wirkliche Bedentung, welche berechnet wird nach der Formel:

$$
v=\frac{q}{d},
$$

wo $q$ das Secundenvolum und $d$ der Querschnitt der betreffenden Arterie. Bei einem kleineren Thier sind natürlicherweise $q$ und $d$ beide kleiner, $v$ aber nur dann, wenn $q$ schneller abnimmt als d. Dogiel fand bei einem Hunde von $23,28 \mathrm{~kg}$ Körpergewicht in der Carotis eine Geschwindigkeit von $489 \mathrm{~mm}$ und bei einem Hunde von $3,66 \mathrm{~kg} \mathrm{Körpergewicht} \mathrm{eine} \mathrm{solche} \mathrm{von} 609 \mathrm{~mm}^{2}$ ).

Nennen wir das totale Secundenvolum des Menschen $Q$, den Querschnitt der menschlichen Aorta $D$, das Secundenvolum der Carotis eines Hundes $q^{\prime}$ und deren Querschnitt $d^{\prime}$, so besteht zwischen der Geschwindigkeit $v$ des Blutes in der menschlichen Aorta und der Geschwindigkeit, $v^{\prime}$, in der Carotis des Hundes die Relation:

1) Ich greife diese Gelegenheit an, ein Irrthum in meiner ersten $\mathrm{Ab}$ handiung über die Blutbewegung (Pflüger's Archiv Bd. 46 S. 178) zu berichtigen, wo jch behaupte, dass schon Dogiel gefunden habe, dass bei der Systole das Herz nie ganz leergepresst wird und dass D. für das Verhältniss des totalen Schlagvoiums, $q$, und der Kammerinhalt, $J$, fand

$$
\frac{q}{J}=0,01 \text { bis } 0,15 \text {. }
$$

Diese Behauptung ist unrichtig weil die genannten Zahlen sich nicht auf das Schlagvolum der Aorta, sondern auf das der Carotis beziehen.

2) Dogiel, Berichte Sächsischer Gesellschaft 867. S. 239 a. 246. 
476 J. L. H o orweg: Ueber die bei einer Systole gelieferte Blutmenge.

$$
V: v^{\prime}=\frac{Q}{D}: \frac{q^{\prime}}{d^{\prime}} .
$$

Wiederum ist $q^{\prime}\left\langle Q\right.$ und $\left.d^{\prime}\right\rangle D$; wer aber kann sagen, welche der beiden Grössen $V$ oder $v^{\prime}$ die grössere ist?

Nehmen wir für $Q$ den grössten aller angegebenen Werthe, die Zahl Volkmann's, also $188 \mathrm{gr}$ fïr jede Systole oder ein Secundenvolum von $210 \mathrm{~cm}^{3}$, so wäre die Geschwindigkeit in der menschlichen Aorta etwa $464 \mathrm{~mm}$, also noch viel geringer als die von $\mathrm{D}_{\mathrm{g}} \mathrm{g}$ i e $\mathrm{l}$ bei einem Hunde von $3,66 \mathrm{~kg}$ Körpergewicht in der Carotis gefundenen Geschwindigkeit von $609 \mathrm{~mm}^{1}$ ). Bei diesem Hunde war das Secundenrolum der Carotis $1,9 \mathrm{~cm}^{3}$. Sei wieder das Secundenvolum der Carotis $1 / 8$ von dem der Aorta, so war hier $Q=15,2 \mathrm{~cm}^{3}$, also noch vielmal geringer als die kleine von mir für das Schlagvolum des menschlichen Herzens gegebene Zahl von $44,7 \mathrm{~cm}^{3}$. Es besteht also gar kein Widerspruch zwischen den Zahlen, die von Dog i el für die Geschwindigkeit in der Carotis des Hundes und den, welche z. B. von Fick und v. Zuntz für das Secundenvolum des Menschen gegeben sind.

1) Dogiel, 1. c. S. 246. 